\title{
EFFECT OF CHANGE IN CONCENTRATION OF ETHYLENE GLYCOL AQUEOUS SOLUTION ON HEAT TRANSFER COEFFICIENT DURING QUENCHING PROCESS
}

\author{
Rahul S. Thakare ${ }^{1}$, Sudhakar S. Umale ${ }^{2}$ \\ ${ }^{I}$ M. Tech. Student, Department of Mechanical Engineering, Sardar Patel College of Engineering, Andheri (W), \\ Mumbai, Maharashtra, India \\ ${ }^{2}$ Associate Professor, Department of Mechanical Engineering, Sardar Patel College of Engineering, Andheri (W), \\ Mumbai, Maharashtra, India
}

\begin{abstract}
Simulation of quenching process of steel is one of the method to plot temperature profile and to calculate HTC at surface of specimen Quenching of medium carbon steel in aqueous solution of ethylene glycol with different concentration of $0 \%$ to $60 \%$ by mass was done using ANSYS 15.5 CFX workbench. Initial temperature of cylindrical specimen was assumed to be $1173 \mathrm{~K}$ and for quenchant it was assumed to be $298 \mathrm{~K}$. Temperature plots for different concentrations and cooling curves at core and surface of the specimen was obtained. Result of cooling curves at different concentration shows that cooling rate for $0 \%$ concentration of ethylene glycol was greatest and it goes on decreasing as concentration of ethylene glycol solution increases. Temperature plots after $10 \mathrm{sec}$. were presented. Results of temperature plots shows that temperature difference between core and surface temperature of specimen is largest in case of $0 \%$ concentration of ethylene glycol solution by mass and it goes on decreases as concentration of ethylene glycol solution by mass increases. In this simulation variation in thermal properties of aqueous solution of ethylene glycol were considered and hence simulation was more accurate. Temperature plots obtained in this simulation will be useful in structural analysis of quenching process to find out residual stresses induced due to temperature gradient.
\end{abstract}

Keywords: Heat Transfer Coefficient (HTC), Ethylene Glycol, Temperature Gradient.

\section{INTRODUCTION}

Heat treatment processes are used to alter mechanical properties of steel in which quenching process is performed to achieve higher hardness. Quenching process involves rapid cooling of steel from its austenite temperature. Due to rapid cooling where cooling rate is higher that critical cooling rate which leads to formation of martensite phase. Martensite phase is hardest phase having highest value of hardness. Cooling rate of solid specimen depends upon quenching medium in which it is cooled. ${ }^{[1]}$ During such process temperature gradient is developed between core and surface of specimen which leads to formation of residual stresses in solid specimen. Present work deals with quenching of medium carbon steel in different quenching medium and study of effect of various quenching medium on heat transfer coefficient and temperature gradient. ${ }^{[2]}$

\subsection{Objective of Present Work}

While carrying out this project attempt is to be made to predict the heat treated components behavior during polymer quenching process by defining the boundary conditions. For improving the material properties this work intends to pursue the application of simulation model and numerical solution to the heat treatment process of medium carbon steel during polymer quenching. The effect of the heat transfer shall be studied to observe variation in cooling rate and to define the heat transfer coefficient.

1. To study the effect of quenching process on EN 9 steel using CFD software.

2. Experimental investigation of quenching process for determination of heat transfer coefficients and hardness of EN 9 steel.

3. To analyze the effect of ethylene glycol concentration on cooling rate of EN 9 steel specimen during quenching.

4. Comparison of CFD and experimental results of the quenching process. ${ }^{[3]}$

\section{METHODOLOGY AND EXPERIMENTAL} WORK

The steps taken in the present experimental work are as:

i. The specimen is heat treated in the furnace at $900^{\circ} \mathrm{C}$ temperature.

ii. The heated specimen is transferred to quenching tank containing polymer solution of ethylene glycol in water.

iii. The variation of temperature with respect to time is measured using thermocouple and temperature indicators.

iv. The Hardness of specimen were measured. ${ }^{[4]}$ 


\subsection{Chemical Composition of EN09 Steel}

\begin{tabular}{|l|l|l|}
\hline Sr. No. & Constituent & \% by mass \\
\hline 1 & C & 0.55 \\
\hline 2 & Mn & 0.90 \\
\hline 3 & P & 0.04 \\
\hline 4 & S & 0.05 \\
\hline 5 & Fe & remaining \\
\hline
\end{tabular}

\subsection{Experimental Setup}

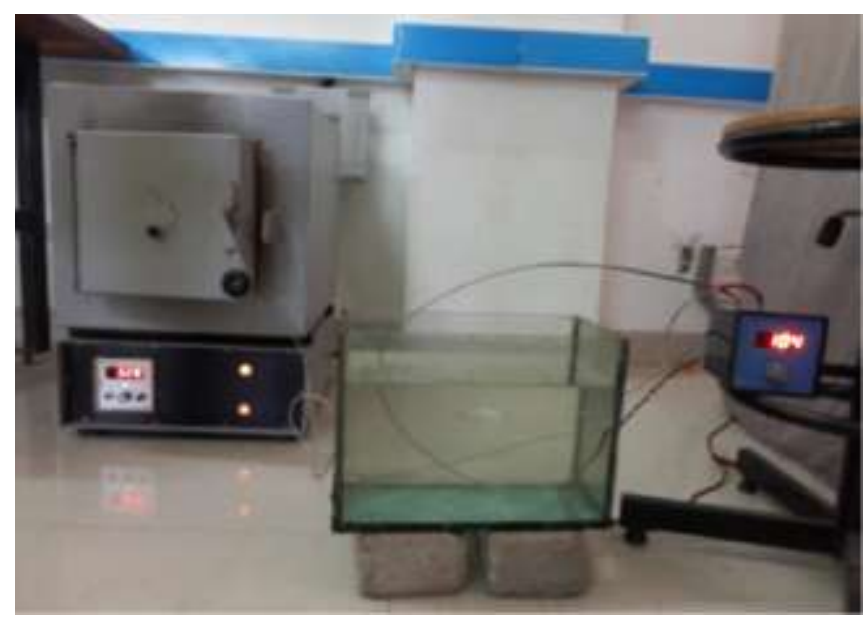

Quenching of EN 9 steel is conducted experimentally. Material of specimen as well as fluid for medium are considered homogeneous. Properties of fluid changes with respect to temperature. Latent heat of phase change solid solid of specimen material is neglected as it has very minor significance considering the whole process.[5] Domain boundaries are considered to be continuously expanding and hence heating of medium due to boundary is neglected. Initially fluid is considered at zero velocity i.e. no convection at start of trial. No agitation is provided to specimen. Temperature at start of trial is uniform for liquid as well as for solid specimen.

\subsection{Solid Specimen Boundary Condition}

At $\mathrm{t}=0 \mathrm{sec}, \mathrm{Ts}=900^{\circ} \mathrm{C}$

Quenching medium initial temperature: $25^{\circ} \mathrm{C}$

Fluid domain size: $30 \mathrm{~cm} \mathrm{X} 30 \mathrm{~cm}$ X $20 \mathrm{~cm}$

Fluid domain Boundary Condition: $\mathrm{Tm}=25^{\circ} \mathrm{C}, \mathrm{P}=1.013$ bar.

\subsection{Nomenclature}

Fig -1: Experimental set up

\begin{tabular}{|l|l|l|}
\hline Sr. No & Discerption & Unit \\
\hline $\mathrm{t}$ & Time & $\mathrm{Sec}$ \\
\hline $\mathrm{T}_{\mathrm{s}}$ & Specimen Temperature & ${ }^{\circ} \mathrm{C}$ \\
\hline $\mathrm{T}_{\mathrm{m}}$ & Quentent Temperature & ${ }^{\circ} \mathrm{C}$ \\
\hline CFD- C & Results of Computational Fluid Dynamics at Centre & - \\
\hline CFD- $\mathrm{S}$ & Results of Computational Fluid Dynamics at Surface & - \\
\hline ACT-C & Actual Experimental Results at Centre & - \\
\hline ACT-S & Actual Experimental Results at Surface & - \\
\hline HTC & Heat Transfer Coefficient & $\mathrm{W} / \mathrm{m}^{2}{ }^{\circ} \mathrm{C}$ \\
\hline
\end{tabular}

\subsection{Heat Treatment of Specimens}

Immersion quench heat treatment of steel refers to the process of heating steel component to the austenitising temperature and immersing it in a suitable fluid medium. The fluid medium is called the quenchant. Quenchants can be of many types; brine, various types of mineral oils, aqueous solutions of polymers, or even plain water. Additional specimens are also made for measuring the toughness and hardness before and after Quenching. Heating is done by using muffle furnace for all specimens by heating to $900^{\circ} \mathrm{C}$ for 15 minutes and then quenched in the water and aqueous solution of ethylene glycol with different concentrations i.e. $20 \%, 40 \%$ and $60 \%$ of $\mathrm{EG}$ in water by volume, finally cooling in open air. The temperature range and hardening/tempering soaking times for the experimental investigations were selected based on the material composition of the specimens. The variation in temperature during quenching is measured by using $\mathrm{K}$ type thermocouple. The variation of temperatures for Centre and surface of specimen are compared. Also hardness of specimen at Centre and surface are measured for different quenchents. Values of hardness for different concentration of ethylene glycol as quenching medium are compared. ${ }^{[3]}$

\section{RESULTS AND DISCUSSIONS}

\subsection{Temperature vs Time Plot for Different Quenching Medium}

Temperature vs time plot for different quenching medium are shown in Fig.2 to Fig.5 
Temperature vs Time For $0 \%$ EG

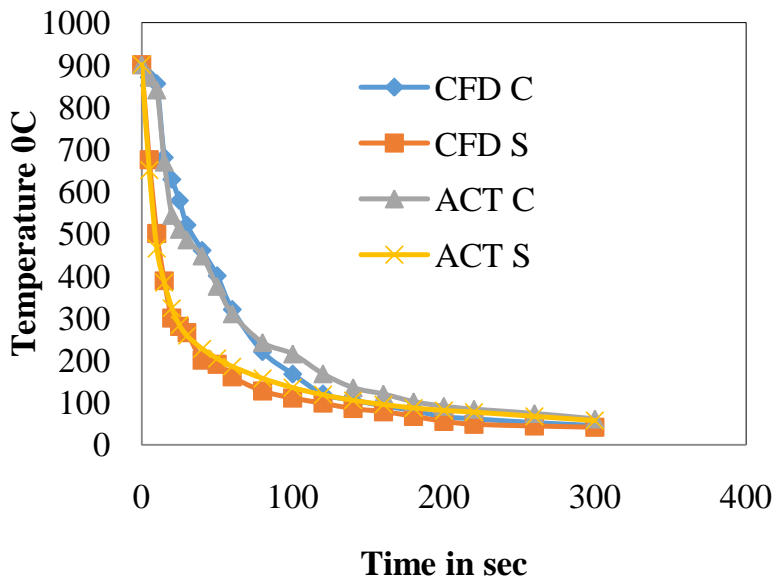

Fig 2: Temperature vs Time for $0 \%$ ethylene glycol aqueous solution

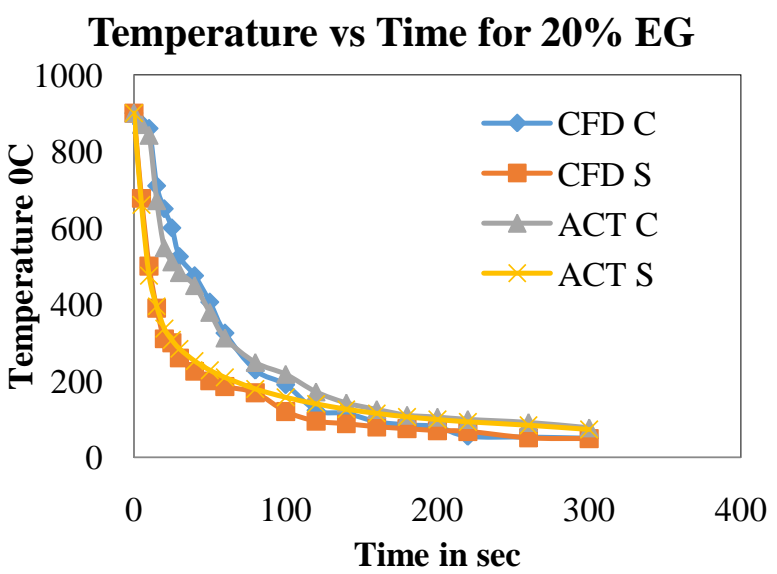

Fig 3: Temperature vs Time for $20 \%$ ethylene glycol aqueous solution

\section{Temperature vs Time for $\mathbf{4 0 \%}$}

EG

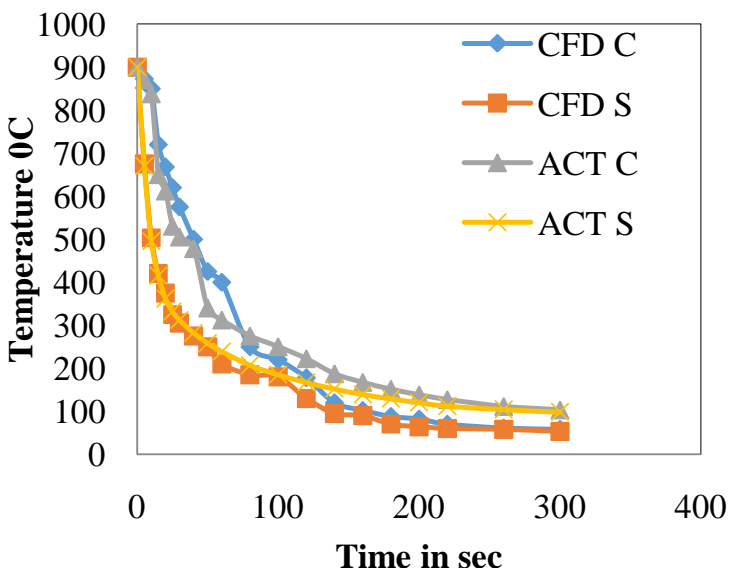

Fig-4: Temperature vs Time for $40 \%$ ethylene glycol aqueous solution
Temperature vs time for $60 \% \mathrm{EG}$

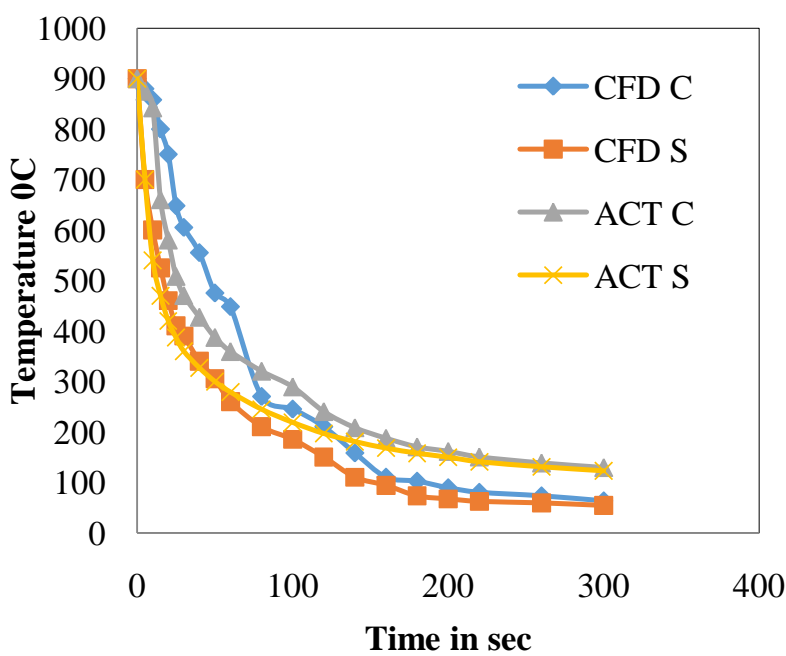

Fig-5: Temperature vs Time for $60 \%$ ethylene glycol aqueous solution

Fig. 2 to Fig. 5 shows variation of temperature with respect to time for centre and surface of specimen. It has been observed that temperature drop for surface is quick compare to core of solid specimen. It results in development of temperature gradient along the solid specimen. Also temperature difference between centre and surface in case of $0 \%$ ethylene glycol aqueous solution is maximum and it goes on decreasing as percentage of ethylene glycol increases in quenching medium. Also results of CFD analysis and experimental analysis have been compared.

\subsection{Heat Transfer Coefficient vs Time Plot for}

\section{Different Quenching Medium}

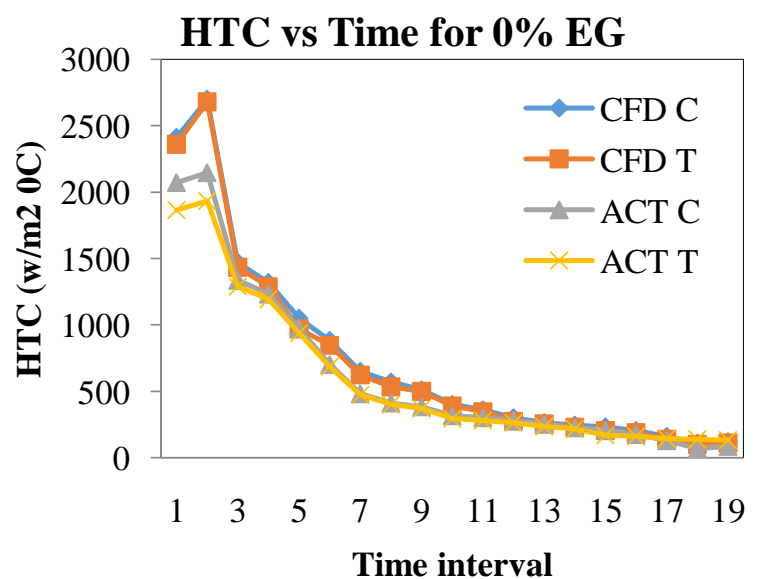

Fig-6: Heat transfer coefficient vs Time for $0 \%$ ethylene glycol aqueous solution 


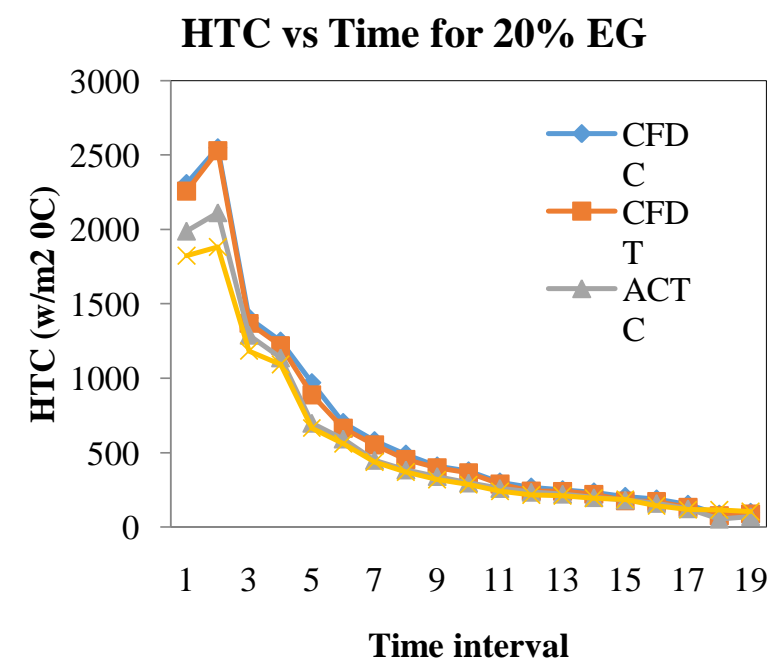

Fig-7: Heat transfer coefficient vs Time for $20 \%$ ethylene glycol aqueous solution

\section{HTC vs Time for $40 \%$ EG}

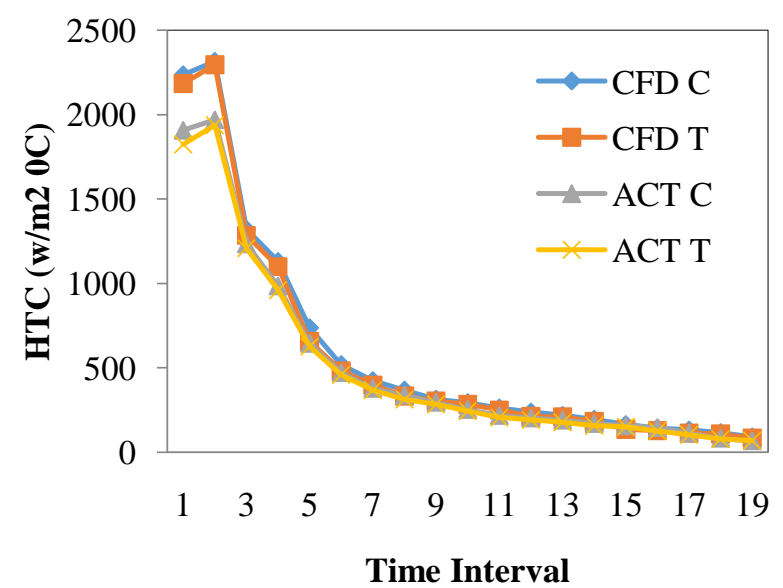

Fig 8: Heat transfer coefficient vs Time for $40 \%$ ethylene glycol aqueous solution

\section{HTC vs Time for $60 \% \mathrm{EG}$}

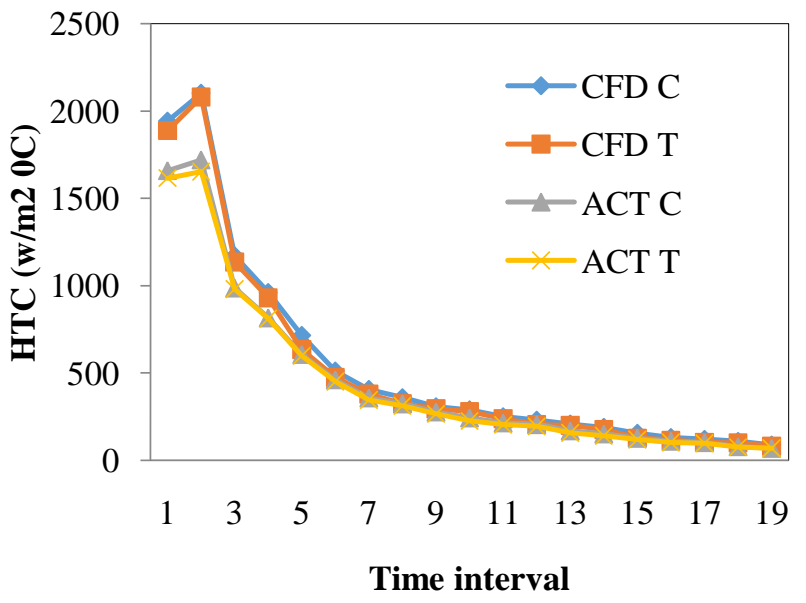

Fig-9: Heat transfer coefficient vs Time for $60 \%$ ethylene glycol aqueous solution
Fig. 6 to fig. 9 shows variation of heat transfer coefficient for curved surface and top surface with respect to time. Heat transfer coefficient and ultimately heat transfer rate is maximum in case of $0 \%$ ethylene glycol solution and it goes on decreasing as percentage of ethylene glycol in quenching medium increases. Results of CFD analysis and experimental analysis have been compared which shows minor deviation in values of heat transfer coefficient.

\section{CONCLUSION}

Based on the outcomes of the heat treatment and quenching process investigations performed on medium carbon steel, the conclusions are:

1) Quenching analysis by CFD for temperature versus time plot shows the reduction in cooling rate of the specimen with increase in concentration of ethylene glycol.

2) The reduced cooling rate results in reduction of temperature difference between surface and core of the specimen.

3) CFD results of Heat transfer coefficient at the curved surface are more as compared to HTC on top and bottom of the specimen at all the times.

4) Experimental results show the reduced cooling rate of the specimen, which indicates the reduction in heat carrying capacity of the mixture with addition of ethylene glycol.

5) The value determined from experimental results for heat transfer coefficient is found to be more for the curved surface of the specimen as compared to that for the top of the specimen.

6) Initially the value of HTC is lower and it increases suddenly, which is the indication of occurrence of nucleate boiling, and then after HTC decreases for both curved as well as top of specimen.

7) Hardness of the specimen decreases with increase in the concentration of ethylene glycol in the mixture.

8) The reduced cooling rate, reduced values of HTC and decrease in the hardness values indicate that the rate of convective heat transfer reduces with addition of EG concentration.

\section{ACKOWLEDGEMENT}

The Authors would like to thank Sapkal Knowledge Hub for providing Experimental Set- Ups for this research work. Invaluable suggestion and guideline provide by Mr. Prafulla Brahme of SKH is also acknowledge.

\section{REFERENCES}

[1]. M Eshraghi Kakhki, M A Golozerand A Kermanpur, "Application of Polymeric Quenchant in Heat Treatment of Crack Sensitive Steel Mechanical Parts: Modelling and Experiments", Material and Design, 32 (2011) 2870-2877.

[2]. Frank Puschmann, EckhardSpecht, "Transient Measurement of Heat Transfer in Metal Quenching with Automized Sprays", Experimental Thermal and Fluid Science, 28(2004)607-615. 
[3]. N Lior, "The Cooling Process in Gas Quenching", Journal of Material Processing Technology, 155-156 (2004) 1881-1888.

[4]. A Buczekand T Telejko, "Inverse Determination of The Boundary Conditions during Boiling Water Heat Transfer in Quenching Operation", Journal of Material Processing Technology, 155-156 (2004) 1324-1329.

[5]. Frank Puschmann, EckhardSpecht, "Transient Measurement of Heat Transfer in Metal Quenching with Automized Sprays", Experimental Thermal and Fluid Science, 28(2004)607-615. 